\title{
Surgical treatment of complex forms of transposition
}

\author{
John W. Kirklin, Alberto Barcia, Philip B. Deverall, Nicholas T. Kouchoukos, \\ and L. M. Bargeron, Jr. \\ From the Departments of Surgery, Diagnostic Radiology and Pediatric Cardiology, \\ School of Medicine, University of Alabama in Birmingham, U.S.A.
}

In spite of the new knowledge developed in recent years surgical treatment for patients with complex forms of transposition of the great arteries remains suboptimal. This is because of the morbidity and mortality that have followed many of the corrective operations, and these are related chiefly to the basic malformation and its secondary effects.

This reviezo summarizes information about surgical treatment of such patients and comments upon some of the implications of this experience.

Appropriate interpretation of data in this area requires a classification of the malformations with clearly defined groups. Many have contributed important information and concepts to this, but the contributions of Van Praagh (Van Praagh, Vlad, and Keith, 1967; Van Praagh and Van Praagh, 1967) have been particularly important. The classification used by us is shown in the Table.

Generally the atria and viscera are in their usual relation. That is, the morphologically right atrium is on the right when the viscera are in situs solitus position, and the left is on the left; and when there is situs inversus of the viscera the right atrium is on the left and the left is on the right. Thus by determining the position of the stomach's gas bubble in the plain chest radiograph one knows the position of the atria. By the 'loop rule' of Van Praagh the position of the morphologic right ventricle can generally be identified from the chest film, since in right-left terms it usually is on the side of the aortic valve and ascending aorta (Van Praagh, Ongley, and Swan, 1964; Guerin et al., 1970). The concordance or discordance in the positions of atria and ventricle can be deduced. Angiocardiography is done to confirm this and the position and interrelations of the great arteries and ventricles, the location of the conus or conuses, and other details.

Transposition of great arteries with intact ventricular septum

Uncomplicated forms of the malformation have been considered in this symposium by Aberdeen and others.
With pulmonary stenosis In recent years it has been appreciated that many of these patients by the age of 3 to 12 months have a difference in the peak pressure between left ventricle and pulmonary artery (Shaher et al., 1967; Tynan et al., 1969) and an angiographic appearance suggesting subvalvar pulmonary stenosis (Shaher, Moes, and Khoury, I967; Deverall et al., 1970). Presumably this was not recognized often in earlier times because so few babies lived beyond the first month of life and because the lesion may be overlooked at necropsy. At present the exact mechanism of the development of the pressure difference and the angiographic appearance is not understood, nor is their functional significance.

About 20 per cent of babies who have an adequate atrial septostomy deteriorate and

TABLE Classification of transposition and related malformations. Pulmonary stenosis can occur in any category. The viscera (and atria) may be in situs solitus or inversus position

I: Concordant position of atria and ventricles

A) Transposition of the great arteries (I) with intact ventricular septum

(2) with ventricular septal defect

B) Double outlet right ventricle

(I) with 'normally' interrelated great arteries

(2) with abnormally interrelated great arteries

C) Double outlet left ventricle

II : Discordant position of atria and ventricles

A) Corrected transposition

(I) with intact ventricular septum

(2) with ventricular septal defect

B) Double outlet right ventricle 
become progressively more cyanotic during the first year of life. Though Tynan and colleagues have attributed this to the development of subvalvar stenosis and secondary reduction of pulmonary blood flow, the published literature and our own experience suggest that only reduction in pulmonary blood flow below about one and one-half to two times systemic blood flow is the common denominator. According to this hypothesis, more of the factors determining left ventricular performance are abnormal and contribute to the relatively small pulmonary blood flow than merely increased load resisting shortening of the sarcomeres of the left ventricle secondary to pulmonary stenosis. Some older children, with a satisfactory clinical response to atrial septostomy and a good result from intra-atrial transposition of venous return by Mustard's technique, have subvalvar narrowing (Fig. I).

In any event, when babies deteriorate and become more cyanosed after a satisfactory balloon septostomy further intervention is necessary. Since left ventricular performance is hypothesized to be poor whatever the cause, intracardiac repair by Mustard's technique is on theoretical grounds unattractive. No reports of a series of such operations in this particular situation in the first year of life are available. We have experience with one such patient, who died 12 hours later of extreme reduction in cardiac output. At present our practice is to make side-to-side anastomosis between ascending aorta and right pulmonary artery (Waterston operation) to increase pulmonary blood flow and arterial oxygen saturation. The left ventricle may enlarge as a result, and its performance after subsequent intracardiac repair may be more appropriate. The results of such a treatment programme are not yet available.

\section{Transposition of great arteries with large ventricular septal defect}

Without pulmonary stenosis The problem in patients with this lesion is obstructive pulmonary vascular disease (Ferguson, Adams, and Watson, 1960; Viles, Ongley, and Titus, 1969). Not only does the usual hypertensive pulmonary vascular disease develop, but thrombotic occlusions of the smaller pulmonary arteries may occur early owing to the polycythaemia and increase pulmonary vascular resistance still further. The recently reported clinical experience from Great Ormond Street Hospital and earlier histological studies indicate that at least moderate elevation of pulmonary vascular resistance (pul-

FIG. I Left ventricular angiocardiogram in a patient with transposition of the great arteries, intact ventricular septum, and subvalvular pulmonary stenosis due to posterior bulging of the ventricular septum. The atria and ventricles are in situs solitus. Pulmonary artery originates from the left ventricle with continuity between anterior leaflet of mitral valve and pulmonary valve. ( $a$ and $b$ ) diastolic phase. ( $c$ and d) systolic phase. This patient underwent intra-atrial transposition of venous return by Mustard's technique without surgical attention to the pulmonary stenosis. He has obtained an excellent result. (Reproduced with permission from Deverall et al., 1970)

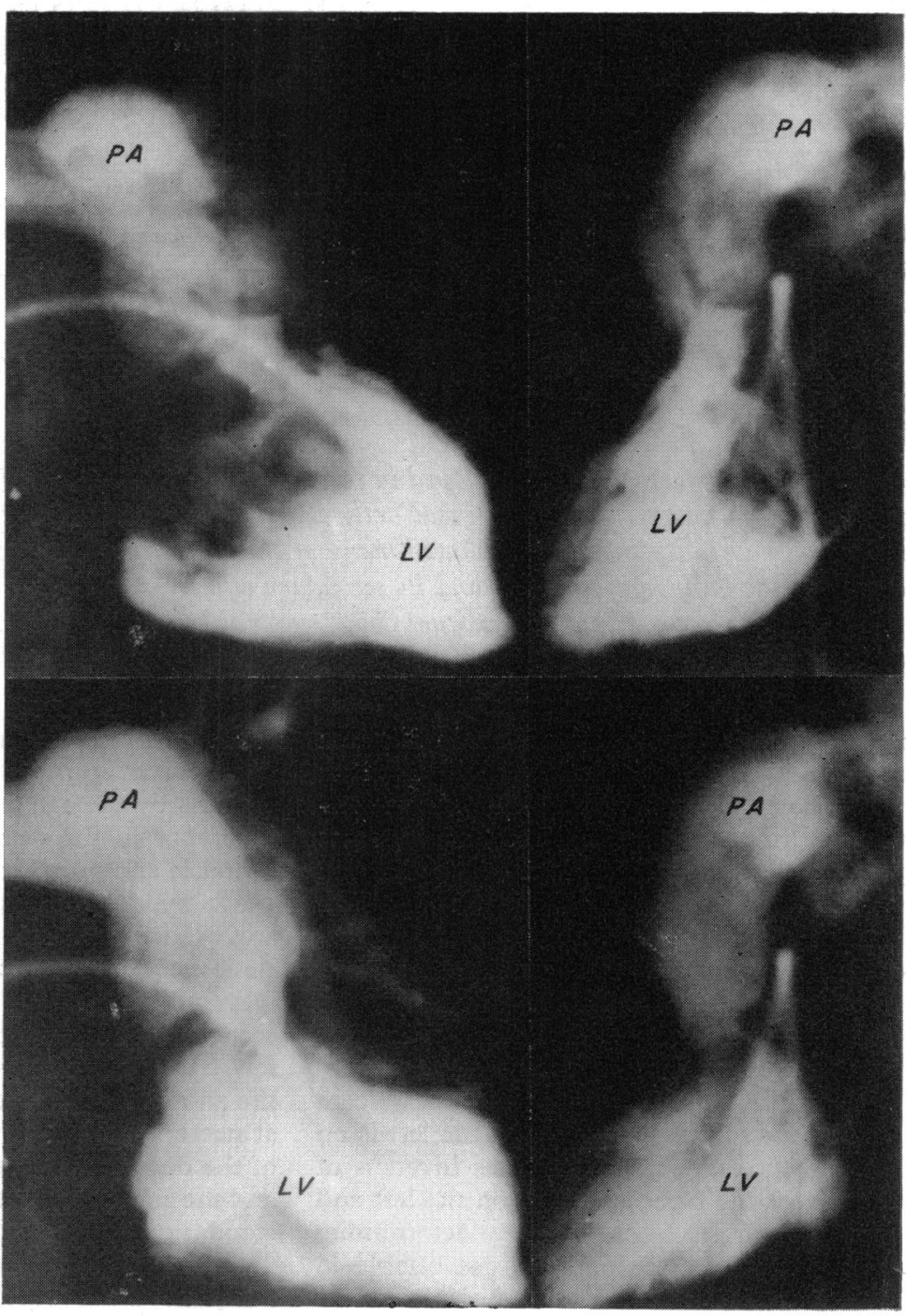

(d) 
monary/systemic resistance ratio $>0.5$ ) is usually present by the age of 1 year. We and others have reported series of patients over this age treated by repair of the ventricular septal defect and intra-atrial transposition of venous return by the Mustard technique (Hightower, Weidman, and Kirklin, 1966; Danielson et al., 1970). The hospital mortality rate is about 50 per cent, and the cases have all had moderate or severe elevation of pulmonary vascular resistance. Although Mair and colleagues at the Mayo Clinic (D. Mair, F. Helmholz, P. A. Ongley, and D. G. Ritter, 1970, personal communication) have recently suggested from a retrospective analysis that selection of cases for surgery on the basis of absolute pulmonary resistance less than 5 to 7 units $/ \mathrm{m}^{2}$ would yield better results, the formidable problem of the salvage of such patients seems unlikely to be solved by this device, since so few have this favourable finding over the age of about I year. It is noteworthy that at a given level of pulmonary vascular resistance the correction of ventricular septal defect and transposition by present techniques is associated with a much higher hospital mortality rate than is repair of isolated ventricular septal defect.

One encouraging approach is creation of an atrial septostomy and pulmonary artery banding in the first few months of life, followed by definitive intracardiac repair at age 2 to 3 years. Waldhausen et al. (1969) have reported success with this management programme in several patients. The banding should be done in the first year of life because of the early development of pulmonary vascular disease in these patients (Stark et al., 1970).

When good palliation from septostomy and banding has been achieved an alternative definitive repair should be considered namely, closure of the ventricular septal defect so that left ventricle ejects into aorta, ligation of banded pulmonary artery, and insertion of valved conduit between right ventricle and pulmonary artery (see below). Ideally, the patients should be about 8 years of age when such a procedure is done, so that a conduit large enough for adult life can be used.

With pulmonary stenosis For about 8 years we have had occasional success in these patients by correcting the pulmonary stenosis, repairing the ventricular septal defect, and performing intra-atrial transposition of venous return by Mustard's technique. Hospital mortality rate has been high, according to Rastelli, Wallace, and Ongley (1969) over so per cent, and many patients were con-

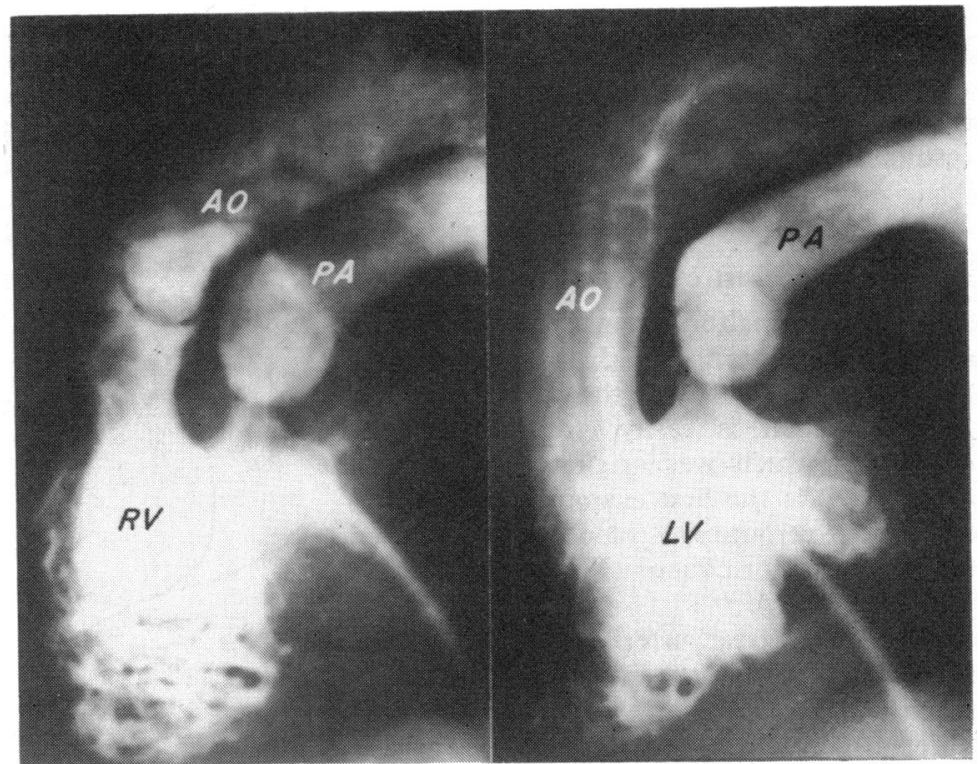

(a)

(b)

FIG. 2 Transposition of the great arteries with situs solitus of atria and ventricles, ventricular septal defect, and severe subvalvular pulmonary stenosis. (a) Aorta originates anteriorly from the right ventricle (RV) with a well-developed conus. (b) Left ventricular angiocardiogram showing the severe subpulmonary stenosis and pulmonary valve doming.

sidered inoperable because of subvalvar narrowing (Fig. 2). However, using this technique Daicoff et al. (1969) have recently reported success in four such patients. Three of their patients may have had only mild pulmonary stenosis, judging from the data presented. Just as in patients with uncomplicated atrial septal defect, a peak pressure gradient of even $40 \mathrm{~mm}$. $\mathrm{Hg}$ across the pulmonary valve may result from a large pulmonary blood flow and only mild pulmonary stenosis.

Rastelli et al. (1969) introduced an ingenious new approach to this problem. The ventricular septal defect is repaired so that the left ventricle ejects across it into the aorta; the stenotic pulmonary artery is ligated; and a valved conduit (in their cases an allograft of ascending aorta with its valve) is placed between right ventricle and distal pulmonary artery. McGoon, Rastelli, and Wallace (1970) have recently reported 12 patients so treated with no hospital deaths. In a smaller group of patients we, too, have been impressed with the smooth postoperative course and low risk of the procedure. The somewhat older age of the patients, the absence of pulmonary 
vascular disease, and perhaps the resultant functionally normal relation between the ventricles and great arteries probably account for the low risk of the procedure. The functional results have been excellent.

Double outlet right ventricle with concordant position of atria and ventricles

When in this malformation the great arteries are normally interrelated the ventricular septal defect is in relation to the subaortic conus. Surgical repair is easily effected, and the operation (which was originally applied by us in 1956) is the first example of the intraventricular rerouting of blood flow now used in several malformations (Kirklin, Harp, and McGoon, 1964).

When the great arteries are abnormally interrelated with aorta and pulmonary artery side-by-side or the aorta to some extent anterior to the pulmonary artery, great variability exists in the relation of the ventricular septal defect to the subpulmonary and subaortic conuses. Classically it is in relation to the subpulmonary conus, and the clinical picture is similar to that of patients with transposition of the great arteries and ventricular septal defect. In this situation the only reconstruction we have found to be feasible is repair of the septal defect so that left ventricular blood is ejected into pulmonary artery (transposition with intact ventricular septum has been created); and then intra-atrial transposition of venous return (Hightower et al., 1969). (Fig. 3.) We have had success in three such cases. The possibility of repairing the defect so that left ventricle ejects now into aorta exists when the ventricular septal defect is in just the proper position. McGoon has reported such a successful repair, though the angiocardiograms and description of the operation suggest that the patient may have had transposition with large ventricular septal defect and the pulmonary artery overriding the defect (Patrick and McGoon, 1968). The pulmonary artery had been banded some years earlier.

When there is double outlet right ventricle with abnormally interrelated great arteries there may of course be pulmonary stenosis. In one such patient, who also had situs inversus of viscera, atria, and ventricles (Fig. 4), we planned creation of an intraventricular tunnel between the defect and aortic infundibulum (to provide for left ventricular ejection into aorta); closure of the pulmonary artery; and insertion of a valved external conduit between right ventricle and pulmonary artery. At operation, and later at necropsy,

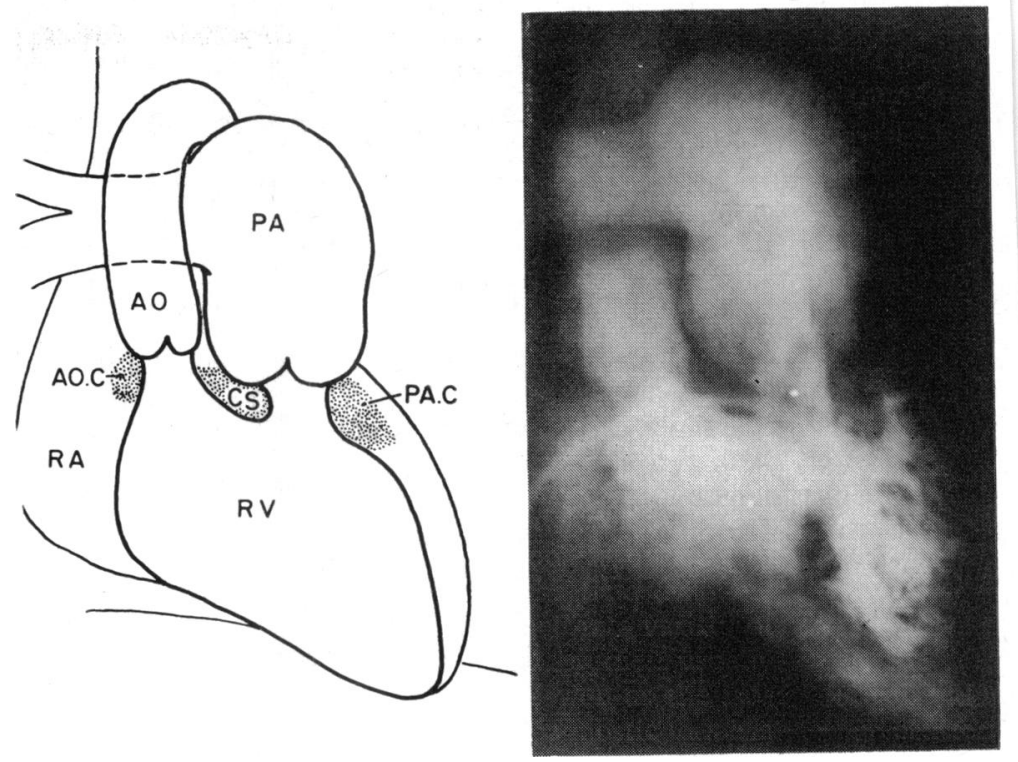

FIG. 3 Right ventricular angiocardiogram in anteroposterior projection in a patient with double outlet right ventricle and abnormally interrelated great arteries. In this case the great vessels are side-by-side with the aorta to the right. Both the aorta and pulmonary artery originate from separate conuses (infundibula) of the right ventricle. The ventricular septal defect is subpulmonary in position. Intracardiac repair was done, and the patient has obtained a good result. (Reproduced with permission from Hightower et al., 1969.)

the defect was found to be of the atrioventricular canal type and there was no possibility of carrying out the planned intraventricular procedure. The case illustrates again that the type and location of the ventricular septal defect are variable in this situation, and that the feasibility and type of repair are dependent upon the relation between the defect and the other structures within the right ventricle.

\section{Double outlet left ventricle}

Rarely both great arteries come off the left ventricle. Van Praagh suggests that in this situation there is not an infundibulum beneath either great artery. In 1968 we operated upon one such patient, who also had severe pulmonary stenosis and was cyanosed and disabled (Kerr et al., 1970). The correct diagnosis was made in the operating room, although retrospectively it was possible to make it from the angiocardiogram. Repair was successfully accomplished by closing the ventricular septal defect, closing the stenotic pul- 
FIG. 5 Corrected transposition of the great arteries, situs solitus of the viscera and atria, discordant position of atria and ventricles, ventricular septal defect, and left (tricuspid) atrioventricular valve insufficiency. $(A$ and $B)$ Injection into morphological left ventricle $(L V)$ located to the right with characteristic shape and smooth appearance. (C and D) Aorta originates from morphological right ventricle $(R V)$. During systolic contractions a jet of contrast material is directed from right ventricle $(R V)$ to dilated left atrium ( $L A)$ through abnormal left atrioventricular valve. (Reproduced with permission from Barcia et al., 1967)

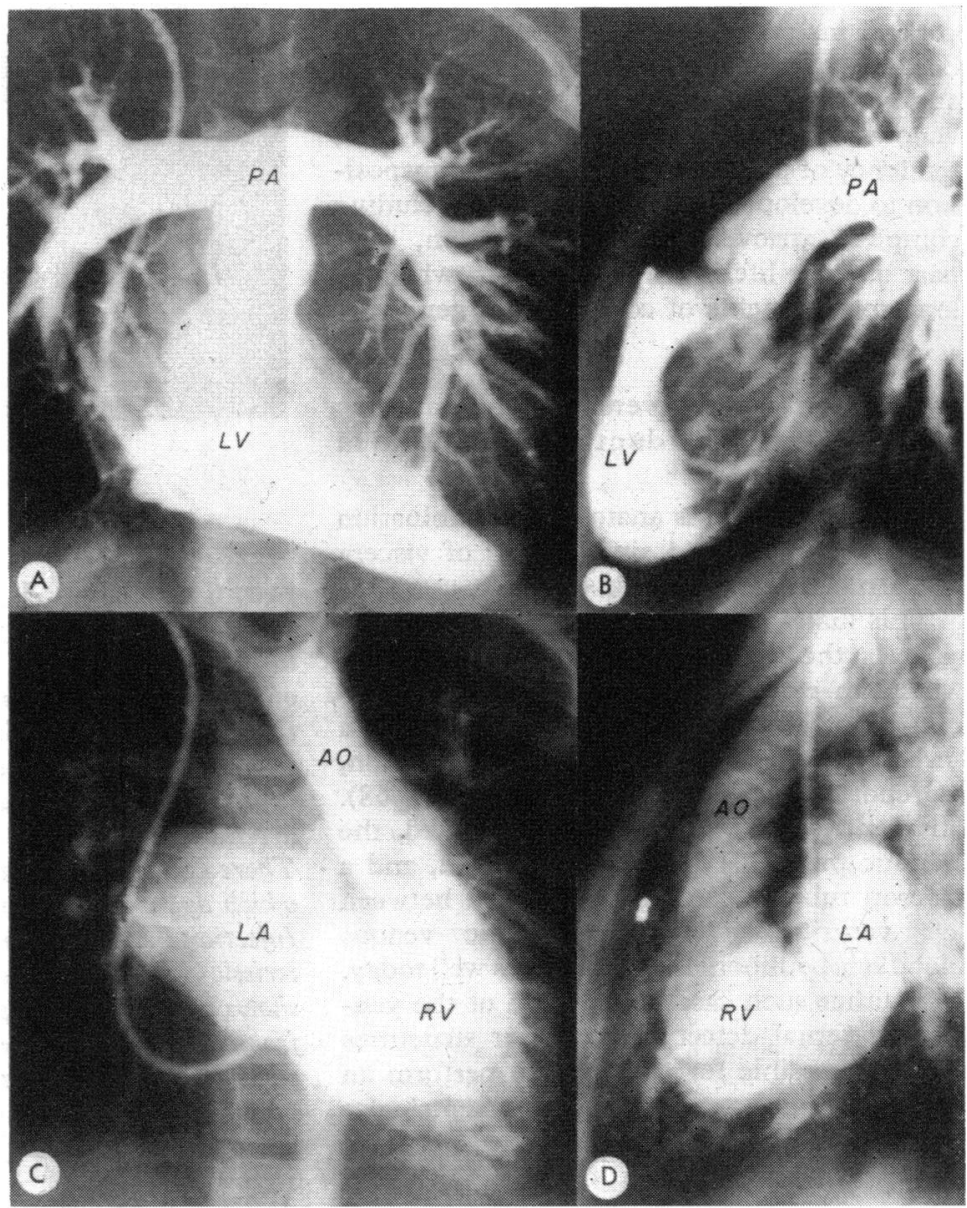

(b)

(c)

c)
FIG. 4 (a) Angiocardiogram made in the lateral projection after right ventricular injecatria, and ventricles (concordant position of atria and ventricles), double outlet right venmonary artery is opacified and severe pulmon ary stenosis is evident. The outline of the aortic cusp is visible anteriorly to the pulmonopacified, a large ventricular septal defect, and partial opacification of left ventricle. (c) permission from Kirklin et al., 1970)

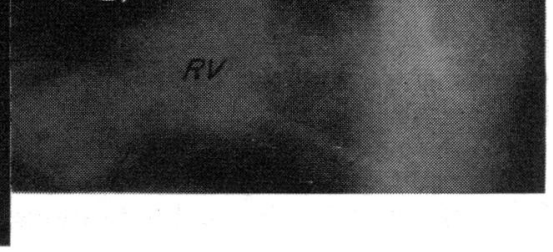


monary valve, and creating an external conduit between right ventricle and pulmonary artery. Since he was a small 4-year-old, a valve was not inserted and the posterior onehalf of the conduit was cardiac tissue in situ, hoping thereby to provide for growth of the conduit as the boy grows. A somewhat similar, but slightly different, malformation has been successfully repaired by Sakakibara and colleagues (1967).

\section{Corrected transposition}

A detailed analysis of this category of complex types of transposition is not possible in this review (Fig. 5). Suffice it to say that the left-sided tricuspid valve may be so severely incompetent as to require replacement, which can be satisfactorily accomplished. When a large ventricular septal defect and indications for its closure are present, this can be done. When there is ventricular septal defect and severe pulmonary stenosis, the stenosis is usually subvalvar. Usually it is impossible to relieve it directly. The ventricular septal defect can be closed and a valved bypassing conduit inserted between left ventricle (which because of the discordant position of atria and ventricles receives right atrial or systemic venous blood) and pulmonary artery. The tendency of patients with corrected transposition to develop serious arrhythmias, including complete atrioventricular dissociation, as a part of their life history limits somewhat the long-term benefits of corrective surgery.

\section{Double outlet right ventricle, pulmonary stenosis, and discordant position of atria and ventricles}

All patients with this anatomical combination seen by us have had situs solitus of viscera and atria and dextrocardia (Fig. 6).

This malformation is of particular interest, as it is the first one, to our knowledge, in which an external conduit was used for rerouting of blood. In 1964 we operated on a severely cyanosed boy with this malformation, as reported by Kiser and colleagues (I968). His ventricular septal defect was closed, the stenotic pulmonary artery was ligated, and a Dacron tubular conduit was placed between left ventricle (receiving systemic venous blood) and pulmonary artery. He is well today. In another such case the relation of the ventricular septal defect to the other structures made it possible for McGoon to perform an intraventricular repair so that left ventricular blood passed across it to the opened pulmonary artery. (a)

(b)
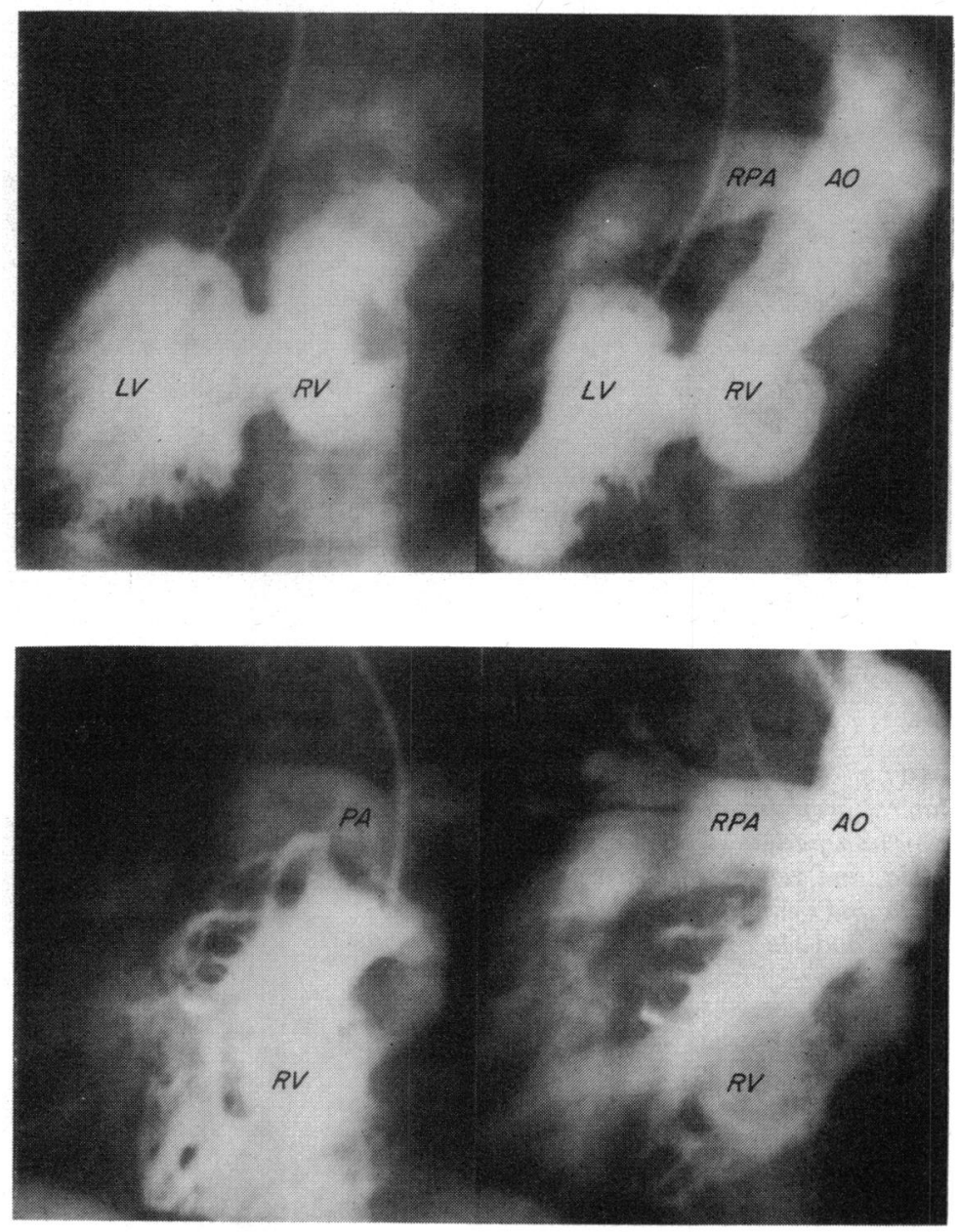

(c)

(d)

FIG. 6 ( $a$ and $b$ ) Angiocardiography made in the anteroposterior projection with injection into left ventricle in a patient with situs solitus of viscera and atria, inversion of the ventricles (discordant position of atria and ventricles), dextrocardia, double outlet right ventricle, and pulmonary stenosis. No great arteries are connected to the left ventricle. There is a large ventricular septal defect across which dye is passing into right ventricle. (c) Injection into right ventricle shows its characteristic coarse trabeculation. (d) A later frame shows both aorta and pulmonary artery arising from right ventricle, and severe pulmonary stenosis. These angiocardiograms are of the patient operated upon by us in 1964. (Reproduced with permission from Hallermann et al., I970.) 


\section{Conclusion}

Knowledge of the morphology, pathophysiology, and diagnosis of these complex forms of transposition is quite advanced. When the diagnosis is not precise or complete preoperatively, appropriate observations at operation by a knowledgeable surgeon will provide a complete and proper diagnosis. When there is concordance of atria and ventricles and, as a part of the malformation, a large ventricular septal defect and no pulmonary stenosis, pulmonary vascular disease usually develops rapidly after the first year of life and severely limits the success of subsequent intracardiac surgery. Pulmonary artery banding should be done during the first year of life, and definitive repair at about age 4 years. Patients with transposition and intact ventricular septum usually do not develop severe pulmonary vascular disease, often receive good palliation from atrial septostomy, and can become pink and asymptomatic after subsequent intraatrial transposition of venous return by Mustard's technique. An enigma is the occurrence in some babies of deepening cyanosis and disability within 3 to 9 months of adequate atrial septostomy. Although subvalvar stenosis appears to be present in many of these, the deterioration seems primarily related to inadequate pulmonary blood flow. This in turn is probably more often related to inadequacies of several of the determinants of left ventricular performance rather than simply to pulmonary stenosis. Uncommon complex varieties of transposition, such as double outlet right ventricle of several types, double outlet left ventricle, and corrected transposition, are under many circumstances surgically correctable.

\section{References}

Barcia, A., Kincaid, O. W., Davis, G. D., Kirklin, J. W., and Ongley, P. A. (1967). Transposition of the great arteries. An angiocardiographic study. American Fournal of Roentgenology, 100, 249.

Daicoff, G. R., Schiebler, G. L., Elliott, L. P., Van Mierop, L. H. S., Bartley, T. D., Gessner, I. H., and Wheat, M. W., Jr. (1969). Surgical repair of complete transposition of the great arteries with pulmonary stenosis. Annals of Thoracic Surgery, 7, 529.

Danielson, G. K., Mair, D. D., Ongley, P. A., Wallace, R. B., and McGoon, D. C. (1970). Repair of transposition of great vessels by transposition of venous return: Surgical considerations and results of operation. Fournal of Thoracic and Cardiovascular Surgery. In the press.

Deverall, P. B., Bargeron, L. M., Jr., Barcia, A., and Kirklin, J. W. (1970). Transposition of the great arteries with pulmonary stenosis: Surgical considerations. In The Natural History and Progress in Treatment of Congenital Heart Disease. Charles C. Thomas, Springfield, Illinois. In the press.
Ferguson, D. J., Adams, P., and Watson, D. (1960). Pulmonary arteriosclerosis in transposition of the great vessels. American fournal of Diseases of Children, 99, 653.

Guerin, R., Soto, B., Karp, R. B., Kirklin, J. W., and Barcia, A. (1970). Transposition of the great arteries: Determination of the position of the great arteries in conventional chest roentgenograms. American fournal of Roentgenology, Radium Ther$a p y$, and Nuclear Medicine. In the press.

Hallermann, F. J., Kincaid, O. W., Ritter, D. G., Ongley, P. A., and Titus, J. L. (1970). Angiocardiographic and anatomic findings in origin of both great arteries from the right ventricle. American fournal of Roentgenology, Radium Therapy, and Nuclear Medicine, 109, 51.

Hightower, B. M., Barcia, A., Bargeron, L. M., Jr., and Kirklin, J. W. (1969). Double-outlet right ventricle with transposed great arteries and subpulmonary ventricular septal defect: The TaussigBing malformation. Circulation, 39-40, Suppl. I, 207.

, Weidman, W. H., and Kirklin, J. W. (I966). Open intracardiac repair for complete transposition of the great arteries. Circulation, 33-34, Suppl. I, 19.

Kerr, A. R., Barcia, A., Bargeron, L. M., Jr., and Kirklin, J. W. (1970). Double outlet left ventricle with ventricular septal defect and pulmonary stenosis: report of surgical repair. American Heart fournal. In the press.

Kirklin, J. W., Harp, R. A., and McGoon, D. C. (I964). Surgical treatment of origin of both vessels from right ventricle, including cases of pulmonary stenosis. Fournal of Thoracic and Cardiovascular Surgery, 48, 1026.

—, Kouchoukos, N. T., Bargeron, L. M., Jr., and Barcia, A. (1970). Double outlet right ventricle (origin of both great arteries from right ventricle) with abnormally interrelated great arteries: anatomic diagnostic, and surgical considerations. In The Natural History and Progress in Treatment of Congental Heart Disease. Charles C. Thomas, Springfield, Illinois. In the press.

Kiser, J. C., Ongley, P. A., Kirklin, J. W., Clarkson, P. M., and McGoon, D. C. (1968). Surgical treatment of dextrocardia with inversion of ventricles and double-outlet right ventricle. Fournal of Thoracic and Cardiovascular Surgery, 55, 6.

McGoon, D. C., Rastelli, G. C., and Wallace, R. B. (1970). Discontinuity between right ventricle and pulmonary artery: surgical correction. Annals of Surgery, 172, 680.

Patrick, D. L., and McGoon, D. C. (1968). An operation for double-outlet right ventricle with transposition of the great arteries. Fournal of Cardiovascular Surgery, 9, 537.

Rastelli, G. C., Wallace, $\dot{R}$. B., and Ongley, P. A. (1969). Complete repair of transposition of the great arteries with pulmonary stenosis: a review and report of a case corrected by using a new surgical technique. Circulation, 39, 83.

Sakakibara, S., Takao, A., Arai, T., Hashimoto, A., and Nogi, M. (1967). Both great vessels arising from the left ventricle. Bulletin of the Heart Institute fapan, 66.

Shaher, R. M., Moes, C. A., and Khoury, G. (1967). Radiologic and angiocardiographic findings in complete transposition of the great vessels with left ventricular outflow tract obstruction. Radiology, 88, 1092.

—, Puddu, G. C., Khoury, G., Moes, C. A. F., and Mustard, W. T. (1967). Complete transposition of the great vessels with anatomic obstruction 
of the outflow tract of the left ventricle. American fournal of Cardiology, 19, 658.

Stark, J., Tynan, M., Tatooles, C. J., Aberdeen, E., and Waterston, D. J. (1970). Banding of the pulmonary artery for transposition of the great arteries and ventricular septal defect. Circulation, 41-42, Suppl. 2, 116.

Tynan, M., Carr, I., Graham, G., and Bonham Carter, R. E. (1969). Subvalvar pulmonary obstruction complicating the postoperative course of balloon atrial septostomy in transposition of the great arteries. Circulation, 39-40, Suppl. I, 223.

Van Praagh, R., Ongley, P. A., and Swan, H. J. C. (1964). Anatomic types of single or common ventricle in man; morphologic and geometric aspects of 60 necropsied cases. American fournal of Cardiology, 13, 367 .
- , and Van Praagh, S. (1967). Anatomically corrected transposition of the great arteries. British Heart fournal, 29, 112.

, Vlad, P., and Keith, J. D. (1967). Transpositions of the great arteries. In Heart Disease in Infancy and Childhood, and ed. Ed. by J. D. Keith, R. D. Rowe, and P. Vlad. Macmillan, New York.

Viles, P. H., Ongley, P. A., and Titus, J. L. (1969). The spectrum of pulmonary vascular disease in transposition of the great arteries. Circulation, 40, 31.

Waldhausen, J. A., Boruchow, I., Miller, W. W., and Rashkind, W. J. (1969). Transposition of the great arteries with ventricular septal defect: palliation by atrial septostomy and pulmonary artery banding. Circulation, 39-40, Suppl. I, 215. 